\title{
Management of sepsis in neutropenic patients: 2014 updated guidelines from the Infectious Diseases Working Party of the German Society of Hematology and Medical Oncology (AGIHO)
}

\author{
Olaf Penack • Carolin Becker • Dieter Buchheidt • Maximilian Christopeit • \\ Michael Kiehl • Marie von Lilienfeld-Toal • Marcus Hentrich • Marc Reinwald • \\ Hans Salwender • Enrico Schalk • Martin Schmidt-Hieber • Thomas Weber • \\ Helmut Ostermann
}

Received: 17 March 2014 / Accepted: 9 April 2014 / Published online: 29 April 2014

(C) The Author(s) 2014. This article is published with open access at Springerlink.com

\begin{abstract}
Sepsis is a major cause of mortality during the neutropenic phase after intensive cytotoxic therapies for malignancies. Improved management of sepsis during neutropenia may reduce the mortality of cancer therapies. Clinical guidelines on sepsis treatment have been published by others. However, optimal management may differ between neutropenic and non-neutropenic patients. Our aim is to give evidencebased recommendations for haematologist, oncologists and intensive care physicians on how to manage adult patients with neutropenia and sepsis.
\end{abstract}

\section{O. Penack $(\bowtie)$}

Department of Hematology, Oncology and Tumourimmunology,

Charité Campus Virchow Klinikum, Augustenburger Platz 1,

13353 Berlin, Germany

e-mail: olaf.penack@charite.de

\section{Becker}

Department of Oncology, Hematology and Stem Cell

Transplantation, Medical Faculty, RWTH Aachen University,

Aachen, Germany

D. Buchheidt $\cdot$ M. Reinwald

3rd Department of Internal Medicine, University Medical Centre

Mannheim, University of Heidelberg, Heidelberg, Germany

M. Christopeit · T. Weber

Internal Medicine IV, Oncology and Hematology, University

Hospital of Martin-Luther-University, Halle (Saale), Germany

\section{Kiehl}

Department of Hematology and Oncology, Klinikum Frankfurt Oder, Frankfurt, Germany

M. von Lilienfeld-Toal

Department of Hematology and Oncology, University of Jena, Jena, Germany
Keywords Guideline $\cdot$ Sepsis $\cdot$ Neutropenia $\cdot$ Management

\section{Clinical significance and methods}

Sepsis is a leading cause of mortality in patients with haematologic malignancies or solid tumours undergoing intensive cytotoxic chemotherapy [29, 168]. Therefore, optimization of diagnosis and management of sepsis could improve outcome of intensive cytotoxic therapies. A number of prior

M. Hentrich

Department of Hematology, Oncology and Palliative Care,

Harlaching Hospital, Munich, Germany

H. Salwender

Department of Hematology and Oncology, Asklepios Hospital Altona, Hamburg, Germany

E. Schalk

Department of Hematology and Oncology, Medical Centre,

Otto-von-Guericke University Magdeburg, Magdeburg, Germany

M. Schmidt-Hieber

Clinic for Hematology, Oncology and Tumourimmunology, HELIOS Clinic Berlin-Buch, Berlin, Germany

H. Ostermann

3rd Department of Internal Medicine, Ludwig-Maximilians

University, Munich, Germany 
guidelines on the management of sepsis have been published $[15,41,43,60,96,106,132,137]$; however, none of these guidelines specifically address diagnosis and management of sepsis in neutropenic patients.

These updated guidelines were written to provide guidance on diagnosis and management of sepsis in the neutropenic host. First, a panel of 13 experts in the field of infectious diseases in haematology and oncology agreed to participate in preparing the guidelines. Second, the guidelines were thematically divided into six subtopics. Then, subcommittees of two to four authors were created, being responsible for literature search in one of the subtopics. We systematically searched Medline for English language publications up to June 2013 using the key terms: sepsis and one of the following: neutropenia, bacteraemia, bloodstream infection (bacteraemia), definition, epidemiology, incidence, risk factors, prognosis, treatment, antibiotic, antifungal, cardiovascular, pulmonary failure, ventilation, renal dysfunction, renal failure, dialysis, haemofiltration, nutrition, hyperglycaemia, steroid, coagulation, growth factor, immunoglobulin and transfusion. Meeting abstracts were not included; however, references generated from published guidelines and reviews were also investigated. The consensus process was performed as an email- and meeting-based discussion group. In a second step, the manuscript draft was peer reviewed by the review committee of the Infectious Diseases Working Party of the German Society of Hematology and Medical Oncology (AGIHO) on October 1st, 2013. In a third step, the guidelines were approved by the assembly of the members on October 20th, 2013. Criteria used to quote levels and grades of evidence are as outlined in Table 1 [88]. The

Table 1 Categories of evidence used in this guideline [88]

\begin{tabular}{cl}
$\begin{array}{l}\text { Category, } \\
\text { grade }\end{array}$ & Definition \\
\hline $\begin{array}{c}\text { Strength of recommendation } \\
\text { A }\end{array}$ & Good evidence to support a recommendation for use \\
B & Moderate evidence to support a recommendation for use \\
C & Poor evidence to support a recommendation \\
D & Moderate evidence to support a recommendation against \\
& use \\
E & Good evidence to support a recommendation against use \\
Quality of evidence & Evidence from $\geq 1$ properly randomized, controlled trial \\
I & Evidence from $\geq 1$ well-designed clinical trial, without \\
II & randomization; from cohort or case-controlled analytic \\
& studies (preferably from $>1$ centre); from multiple time- \\
& series; or from dramatic results from uncontrolled \\
experiments
\end{tabular}

first draft of the manuscript was written by the subcommittees. The final version of the manuscript was prepared by the corresponding author and has been approved by all authors.

\section{Definitions}

A formal definition of sepsis has long been tried by several researchers and must lack specificity given the broad spectrum of reactions to pathogens.

We suggest using the diagnostic consensus criteria for sepsis adapted to neutropenic patients (Table 2) [97, 98]. In neutropenic patients, the white blood cell count cannot be used as a criterion to define sepsis. The definitions of severe sepsis and septic shock remain unchanged and refer to sepsis-induced organ dysfunction (Table 3).

Table 2 Diagnostic criteria for sepsis during neutropenia [97, 98]. In neutropenic patients, cytopenia cannot be used as a criterion to define sepsis

General parameters

Fever (core temperature $>38.3{ }^{\circ} \mathrm{C}$ )

Hypothermia (core temperature $<36.0^{\circ} \mathrm{C}$ )

Heart rate ( $>90 \mathrm{bpm}$ or $>2$ SD above the normal value for age)

Tachypnoea ( $>30 \mathrm{bpm})$

Altered mental status

Significant edema or positive fluid balance ( $>20 \mathrm{~mL} / \mathrm{kg}$ over $24 \mathrm{~h}$ )

Hyperglycaemia (plasma glucose $>110 \mathrm{mg} / \mathrm{dL}$ or $>7.7 \mathrm{mmol} / \mathrm{L}$ ) in the absence of diabetes

Inflammatory parameters

Plasma $\mathrm{C}$ reactive protein or plasma procalcitonin $(>2 \mathrm{SD}$ above the normal value)

Haemodynamic parameters

Arterial hypotension (systolic blood pressure $<90 \mathrm{mmHg}$, mean arterial pressure $<70 \mathrm{mmHg}$, or a systolic blood pressure decrease $>40 \mathrm{mmHg}$ in or $<2 \mathrm{SD}$ below normal for age)

Mixed venous oxygen saturation $(>70 \%)$

Cardiac index $\left(>3.5 \mathrm{~L} / \mathrm{min} / \mathrm{m}^{2}\right)$

Organ dysfunction parameters

Arterial hypoxaemia $(\mathrm{PaO} 2 / \mathrm{FIO} 2<300)$

Acute oliguria (urine output $<0.5 \mathrm{~mL} / \mathrm{kg} / \mathrm{h}$ for $\geq 2 \mathrm{~h}$ )

Creatinine increase $(\geq 0.5 \mathrm{mg} / \mathrm{dL})$

Coagulation abnormalities (international normalized ratio $>1.5$ or activated partial thromboplastin time $>60 \mathrm{~s}$ )

Ileus (absent bowel sounds)

Hyperbilirubinemia (plasma total bilirubin $>4 \mathrm{mg} / \mathrm{dL}$ or $70 \mathrm{mmol} / \mathrm{L}$ )

Tissue perfusion parameters

Hyperlactataemia (>3 mmol/L)

Decreased capillary refill or mottling 
Table 3 Definitions of severe sepsis and septic shock

\begin{tabular}{|c|c|}
\hline $\begin{array}{l}\text { Severe } \\
\text { sepsis }\end{array}$ & $\begin{array}{l}\text { Sepsis with new signs of organ dysfunction or a decrease in } \\
\text { organ perfusion (lactate acidosis, oliguria }(<30 \mathrm{~mL} / \mathrm{h} \text { or } \\
<0.5 \mathrm{~mL} / \mathrm{kg} / \mathrm{h}) \text {, hypotension }(<90 \mathrm{mmHg} \text { or decrease of } \\
>40 \mathrm{mmHg}) \text {, mental alteration) }\end{array}$ \\
\hline $\begin{array}{l}\text { Septic } \\
\text { shock }\end{array}$ & $\begin{array}{l}\text { Severe sepsis and hypotension persistent despite adequate } \\
\text { fluid substitution and exclusion for other reasons for } \\
\text { hypotension }\end{array}$ \\
\hline
\end{tabular}

\section{Incidence}

Systematic data evaluating the overall incidence of neutropenic sepsis in cancer patients are lacking. The incidence of febrile neutropenia and bacteraemia has been studied more in detail, albeit the majority of studies did not use uniform definitions, include at least partly non-neutropenic patients and focus on distinct patient subgroups. Patients with solid tumours develop febrile neutropenia in around 10-40\%, but this complication might occur in more than $80 \%$ of patients with haematological malignancies $[1,54]$. In patients with indwelling central venous catheters (CVC), febrile neutropenia is frequently caused by catheter-related or catheterassociated bacteraemia with an incidence of around 10-20/ 1,000 neutropenic days $[16,34]$. Likewise, translocation of gut organisms, such as vancomycin-resistant enterococci (VRE), may cause bacteraemia and, ultimately, sepsis in neutropenic cancer patients in up to $40 \%$ of colonized patients [30, 101, 154].

It can be assumed that $>50 \%$ of patients with febrile neutropenia or bacteraemia develop sepsis using the consensus definition. Severe sepsis and septic shock, which have been investigated in a few prospective and retrospective analyses, might occur in up to $20-30$ and 5-10\% of patients with febrile neutropenia, respectively [6, 78, 81, 95, 109, 112].

The increasing numbers of elderly patients undergoing intensive treatment modalities and patients infected with treatment-resistant organisms led to the assumption that the frequency of neutropenic sepsis will increase [11].

\section{Risk factors and prognosis}

Prospective data of risk factors and prognosis for sepsis in adult neutropenic patients are rare $[6,63,78]$.

\section{Risk factors for bacteraemia}

There are few data on risk factors for bacteraemia during neutropenia. Apostolopoulou et al. observed a significant higher rate of bacteraemia, potentially resulting in sepsis, in patients with neutropenia $<0.5 \mathrm{~g} / \mathrm{L}$. Additionally, acute myeloid leukaemia, a prolonged hospital stay, a Hickman catheter, or pre-treatment with antibiotics, chemotherapy or surgery were significantly associated with BSI in haematological and oncological patients [16].

Risk factors for development of severe sepsis

The presence of hypophosphataemia $(<0.8 \mathrm{mmol} / \mathrm{L})$ and hypoproteinaemia $(<62 \mathrm{~g} / \mathrm{L})$ have been identified as risk factors for severe sepsis in febrile neutropenia [78]. The development of septic shock in febrile neutropenia is independently predicted by the presence of pulmonary infection, tachypnoea, increased serum levels of procalcitonin $(\geq 1.5 \mathrm{ng} / \mathrm{mL})$, high lactate levels [6, 109], decreased serum levels of bicarbonate $(<17 \mathrm{mmol} / \mathrm{L})$, antithrombin $(<70 \%)$ or factor VIIa $(<0.8 \mathrm{ng} / \mathrm{mL})[63,78,109,135]$. A low Multinational Association for Supportive Care in Cancer (MASCC) risk index score of $<21$ is associated with an increased risk for septic shock in febrile neutropenic patients [6].

\section{Prognosis}

Prolonged neutropenia $<0.5 \mathrm{~g} / \mathrm{L}$ or the delayed initiation of antibiotics is associated with poor clinical outcome in neutropenic patients with sepsis $[5,103]$. Severe sepsis and septic shock negatively influence outcome [64, 95, 162]. A recent prospective study demonstrated mortality rates of $35 \%$ in severe sepsis, $47 \%$ in septic shock and $85 \%$ in multi-organ failure in patients with haematological malignancies [19]. Factors that were significantly associated with hospital survival included remission of malignant tumour and time to intensive care unit (ICU) admission $<24 \mathrm{~h}$. Negative predictive factors for hospital survival were as follows: allogeneic haemopoietic stem cell transplantation (HSCT), poor performance status, invasive pulmonary aspergillosis, malignant organ infiltration and acute respiratory failure. In another study, Legrand et al. identified prognostic factors for neutropenic patients with severe sepsis or septic shock: The appearance of acute non-infectious complications, of neurological, respiratory or hepatic dysfunction, the need for vasopressor therapy, or older age increased the mortality. On the other hand, the early removal of a CVC and combined antibiotic therapy were associated with higher survival [95].

\section{Microbiology}

Blood cultures as part of the usual microbiological work-up as per local protocol (including urine cultures, stool cultures etc.) remain the gold standard for the diagnosis of bacteraemia and fungaemia. Blood cultures should be standardized in terms of volume, culture sets, frequency, processing, interpretation and reporting. 
However, although most episodes of febrile neutropenia are assumed to be caused by an infection, blood cultures are positive in less than $30 \%$ of febrile neutropenic episodes [48]. Typical organisms causing sepsis during neutropenia are summarized in Table 4.

The epidemiology of gram-positive versus gram-negative bacteraemia varies in different countries [115]. In contrast to other countries, Germany has a predominance $(>50 \%)$ of gram-positive bacteria as the cause for febrile neutropenia [45]. Knowledge about the local epidemiology is essential for a rational choice of empirical antibiotic therapy as already pointed out by others. This is particularly true for colonization with resistant bacteria, since these have been associated with an increased risk of bacteraemia with these pathogens [101].

PCR-based methods to detect bacterial and fungal DNA have yet to be validated in larger cohorts $[8,93,105,120$, 164]. In contrast, PCR-based methods play a definitive role in the diagnosis of viral infections, which may cause sepsis in severely immunocompromised patients [71, 102, 129].

\section{Treatment}

Antimicrobial treatment

Empirical antimicrobial treatment using broad-spectrum antibiotics must be started immediately in neutropenic patients with sepsis (AII). A large retrospective study including more than 2,000 patients showed that during severe sepsis, effective antimicrobial administration within the first hour of documented hypotension is associated with increased survival [95]. In this study, each hour of delay in antimicrobial administration over the ensuing $6 \mathrm{~h}$ was associated with an average decrease in survival of $7.6 \%$ [95].

Table 4 Typical pathogens during bacterial sepsis in neutropenic patients

\begin{tabular}{|c|c|}
\hline Origin & Frequent pathogens \\
\hline Unknown & $\begin{array}{l}\text { Coagulase-negative Staphylococci, Escherichia coli, } \\
\text { Enterococcus species }\end{array}$ \\
\hline Lung & $\begin{array}{l}\text { Pseudomonas aeruginosa, Streptococcus pneumoniae } \\
\text { (pneumococci), Viridans (alpha-haemolytic) streptococci, } \\
\text { Acinetobacter species }\end{array}$ \\
\hline Abdomen & $\begin{array}{l}\text { Escherichia coli, P. aeruginosa, Clostridium spp., } \\
\text { Enterococcus spp., Klebsiella species }\end{array}$ \\
\hline Urogenital & $\begin{array}{l}\text { Escherichia coli, Klebsiella species, Pseudomonas } \\
\quad \text { aeruginosa }\end{array}$ \\
\hline Soft tissue & Staphylococcus aureus, alpha-haemolytic streptococci \\
\hline $\mathrm{CVC}$ & $\begin{array}{l}\text { Coagulase-negative Staphylococci, Coryneform bacteria, } \\
\text { Propionibacterium species, Candida albicans, Candida } \\
\text { tropicalis, Candida parapsilosis, Stenotrophomonas } \\
\text { maltophilia }\end{array}$ \\
\hline
\end{tabular}

$C V C$ central venous catheter
In neutropenic patients with sepsis, results from randomized controlled trials are lacking, and recommendations are based on study results from non-neutropenic patients as well as on expert opinions. We recommend initial treatment with meropenem or with imipenem/cilastatin or with piperacillin/ tazobactam (AIII).

Meta-analyses show that a combination treatment with aminoglycosides increased renal toxicity without improving efficacy in neutropenic patients with bacteraemia [125-127]. However, in a retrospective study, the use of $\beta$-lactam antibiotic/aminoglycoside combinations were associated with superior outcome, as compared with single-agent antimicrobial treatment, in neutropenic patients with severe sepsis and septic shock [95]. Another retrospective study showed reduced hospital mortality in non-neutropenic patients with severe bacterial sepsis after combination therapy comprising at least two antibiotics of different mechanisms versus antibiotic monotherapy [92]. Taken together, a combination treatment with an aminoglycoside may be considered in neutropenic patients with septic shock and severe sepsis (BIII).

Knowledge of local microbiology data is crucial for the choice of antimicrobial agents. Importantly, local resistance patterns as well as colonization with resistant bacteria have to be considered [101]. If infection due to bacteria with frequent resistance to carbapenems or piperacillin/tazobactam is suspected, a specific antibiotic should be added (BIII). If a specific organ infection is suspected, antibiotic therapy should be adapted accordingly. Recommendations on antifungal therapy during neutropenia were recently published by our group and by others $[55,104,118,157]$.

\section{Treatment of cardiovascular insufficiency}

Aggressive and early goal-directed treatment aiming at restoration of cardiovascular function is crucial [42, 140]. To restore adequate cardiac filling pressures and to maintain adequate organ perfusion (goal, mean arterial pressure $65 \mathrm{mmHg}$, central venous pressure $8-12 \mathrm{mmHg}$, pulmonary wedge pressure $12-15 \mathrm{mmHg}$, urinary output $0.5 \mathrm{~mL} / \mathrm{kg} / \mathrm{h}$ and central venous or mixed venous oxygen saturation $70 \%$ ), crystalloid fluids are recommended as the initial fluid of choice in severe sepsis and septic shock. Compared to crystalloids, randomized controlled trials did not show beneficial effects of colloids, especially hydroxyethyl starches for fluid resuscitation in sepsis $[32,62,128]$. However, the risk of acute kidney injury requiring renal replacement therapy is substantially increased by the use of hydroxyethyl starch (EI) [128].

While a large randomized study indicated that albumin administration was safe and equally effective as $0.9 \%$ saline [50], a meta-analysis of data from 17 randomized trials found that the use of albumin-containing solutions for fluid resuscitation of patients with sepsis was associated with lower mortality compared with crystalloids [40]. However, in a 
multicenter randomized trial $(n=794)$ in patients with septic shock, the use of albumin therapy did not significantly reduce 28-day mortality compared to saline solution [50]. Thus, albumin-containing solutions may be used for fluid resuscitation of patients with sepsis and septic shock (CII).

If a sufficient mean arterial pressure $(>65 \mathrm{mmHg})$ cannot be achieved by volume substitution in a reasonable time frame, treatment with vasopressors is indicated. The drug of choice to elevate the vasotonus is norepinephrine in a dose of $0.1-1.3 \mu \mathrm{g} / \mathrm{kg} / \mathrm{min}$ (BII) [48].

In retrospective and small prospective studies, vasopressin (0.01-0.04 U/min) increased urinary output and creatinine clearance compared to norepinephrine [51-53]. However, in the large VASST trial, no reduction in 28-day mortality was found in the vasopressin group, and there is currently poor evidence to support the use of vasopressin in septic shock (CI) [54]. In case of sepsis-related myocardial depression leading to low cardiac output despite adequate volume substitution, vasopressor treatment with dobutamine should be instituted (AII) [140]. Of note, results from an observational study suggest that dopamine administration may be associated with increased mortality rates in septic patients [142].

Bicarbonate therapy is not recommended for the purpose of improving haemodynamics or reducing vasopressor requirements in the presence of lactic acidosis and $\mathrm{pH}>7.15$ (DII) $[38,108]$.

\section{Treatment of pulmonary failure}

Pneumonia leading to acute respiratory failure is a major cause of sepsis in neutropenic cancer patients [19, 20]. On the other hand, severe sepsis may lead to acute lung injury/acute respiratory distress syndrome (ARDS) [145].

In cooperative and awake patients with mild to moderate pulmonary failure, non-invasive positive pressure ventilation should be preferred (AII) [19, 37, 69, 70, 145]. Both noninvasive treatment options led to a significant reduction of intubation compared to the control group in neutropenic cancer patients $[19,73]$. An early start of non-invasive ventilation, prior to development of severe hypoxaemia, is favourable (BII) [21]. Failure of non-invasive ventilation occurs in half of the critically ill haematologic patients and is associated with an increased mortality [21]. Predictors of noninvasive ventilation failure are as follows: high respiratory rate, short time between admission and non-invasive ventilation [21], vasopressor use, renal replacement therapy and the development of ARDS [3].

In moderate to severe respiratory insufficiency, endotracheal intubation and mechanical ventilation are necessary. Survival is positively correlated to the experience of the ICU with haematologic and oncologic patients [171]. In a retrospective multicenter study of allogeneic HSCT recipients admitted to the ICU, mechanical ventilation was associated with low survival rates [107]. These data were confirmed in a prospective study [19].

Percutaneous extracorporeal membrane oxygenation showed to be a rescue therapy to bridge hypoxemia due to ARDS in patients with oncological or malignant haematological diseases [59, 99, 111]. Further studies are needed in this field, before a recommendation can be given.

\section{Management of renal dysfunction}

Acute kidney injury (AKI) develops in approximately $20 \%$ of patients with severe sepsis and $50 \%$ with septic shock. The combination of acute renal failure and sepsis is associated with a $70 \%$ mortality [144]. Specific data for neutropenic patients are lacking, and recommended management of renal dysfunction is not different from non-neutropenic patients.

In short, no clear guidelines on the timing of the initiation of renal replacement therapy (RRT) can be given. Regarding the mode of replacement therapy, intermittent haemodialysis and continuous renal replacement therapies (CRRT) are equivalent in patients with sepsis and AKI (BI) $[57,58,84$, $100,134,155]$. In haemodynamically unstable patients, control of fluid balance may be facilitated by the use of CRRT (BII) $[42,79]$.

Increasing the frequency of RRT is thought to reduce the rate of uremic complications and improve outcome in patients with AKI. However, randomized controlled studies showed conflicting results $[42,79,138]$. A recent meta-analysis indicates that high-dose RRT in critically ill patients with AKI does not improve patient survival or recovery of renal function as compared with less-intensive regimes $[75,122,160]$. Thus, no firm recommendations can be given for the increased frequency of RRT (CI).

In patients undergoing renal replacement therapy, the dosage of antimicrobial substances should be carefully checked and adjusted [86]. The use of low-dose dopamine for protection of renal function is not recommended (EI) $[26,85]$.

Nutrition and control of metabolic functions

\section{Caloric intake}

Most recommendations reported are extrapolated from analyses in critically ill and well-nourished patients without neutropenia. Enteral nutrition is preferred over parenteral nutrition unless contraindicated or impossible, as it is associated with a lower rate of infections (BII) [67]. Enteral caloric intake should be calculated according to the phase of sepsis: during the initial phase of sepsis, the supply of $>20-25 \mathrm{kcal} / \mathrm{kg}$ ideal bodyweight (IBW) has been associated with inferior outcome in one observational study (DIII) [91]. During recovery, 25$30 \mathrm{kcal} / \mathrm{kg}$ IBW should be provided (BIII) [89, 149]. 


\section{Supplements}

As reproducible mortality benefits for supplementation of arginine [31, 56], omega-3 fatty acids [24, 130, 131] and combined formulations $[27,56,68]$ in patients with severe sepsis and septic shock are lacking, we do not recommend general use of either of these supplements (DII). Substitution of glutamine did not positively affect the primary survival endpoint in two randomized trials including together over 1,000 patients with sepsis $[9,66]$ and significantly increased in-hospital and 6-month mortality in the REDOXS study [66]. Therefore, glutamine substitution cannot be recommended (EI).

Two recent large randomized two-factorial trials compared the influence of lower doses of selenium substitution to placebo in critically ill patients $[9,66]$. In these trials including 282 and 826 septic patients, respectively, selenium substitution had no effect on mortality $[9,66]$. In a smaller trial, higher dose selenium substitution $(1,000 \mu \mathrm{g}$ daily) was associated with mortality reduction only in the per protocol analysis [10]. In a meta-analysis including nine trials with septic patients, selenium substitution was associated with lower mortality, especially in patients receiving selenium in higher doses ( $\geq 1,000 \mathrm{mg}$ daily) and for $\geq 6$ days [74]. Thus, further clinical trials regarding the adequate dosing and treatment duration are needed before treatment with selenium can be recommended (DI).

\section{Hyperglycaemia}

Hyperglycaemia in patients requiring intensive care is associated with an inferior outcome [23, 47]. Results of clinical trials in patients with severe sepsis and septic shock $[13,32]$ as well as clinical trials $[51,133,158]$ including patients with underlying malignant disease [158] and a meta-analysis [61] in mixed populations of critically ill patients failed to show a benefit of intensified insulin therapy. These results are in contrast to the results of the initial trial by van den Berghe et al. [159] which had suggested a benefit of a tight blood glucose control (blood glucose level of 4.4-6.6 mmol/L (80$120 \mathrm{mg} / \mathrm{dL})$ ). Thus, we do not recommend intensive insulin therapy aiming at a blood glucose level of 4.4-6.6 mmol/L $(80-120 \mathrm{mg} / \mathrm{dL}$; EI). Based on these data and international guidelines [44, 76, 137], we recommend to maintain blood glucose levels at least $\leq 9.9 \mathrm{mmol} / \mathrm{L}(\leq 180 \mathrm{mg} / \mathrm{dL}$; BIII). A high variability of blood glucose levels in septic patients should be avoided, as this is associated with increased mortality (BIII) [7, 22, 46].

Treatment with corticosteroids

Replacement of an impaired adrenal reserve and antiinflammatory properties is a rationale for studying corticosteroids as an adjunctive to sepsis therapy. The use of corticosteroids in sepsis has not been studied in a prospective fashion for neutropenic patients. In the CORTICUS trial, 84 cancer patients were included; however, no subgroup analysis of these patients has been published [35].

High-dose corticosteroid treatment $>300 \mathrm{mg}$ hydrocortisone per day)

Randomized controlled trials and meta-analyses reported on increased overall mortality and increased mortality from secondary infections in non-neutropenic patients with sepsis receiving high-dose steroids $[28,39,113,153,163]$. Thus, highdose corticosteroids are not recommended as treatment of sepsis (EI).

\section{Low-dose corticosteroid treatment ( $\leq 300 \mathrm{mg}$ hydrocortisone} per day)

Substitutive doses of hydrocortisone during sepsis remain controversial. Annane et al. identified a benefit in 28-day mortality for the treatment group [14]. The CORTICUS trial did not reveal a difference in 28-day mortality between treatment and placebo and found a higher incidence of hyperglycaemia, hypernatraemia and secondary infections in the treatment group [152]. The results of meta-analyses have been similarly contradictory. Some meta-analyses support the use of low doses of hydrocortisone [12, 114, 150], while others do not support the use of low doses of hydrocortisone $[80,116,146]$. Newer data from three observational studies with a total of over 25,000 patients from sepsis registries showed no mortality benefit for low-doses steroids [25, 33, 49]. Thus, we do not recommend the routine use of substitutive doses of hydrocortisone in neutropenic patients with sepsis (DI). However, low-dose corticoid treatment may be considered in patients with insufficient restoration of blood pressure levels despite adequate fluid resuscitation and vasopressor treatment (BII) [124]. The results of three ongoing large randomized controlled trials will hopefully further clarify the role of low-dose steroids in severe sepsis.

Treatment with coagulation inhibitors

In sepsis, the coagulation cascade is frequently activated at early time points. As thrombocytopenia and an increased risk of bleeding are frequently present in patients with cancer and chemotherapy, attempts to positively influence coagulation in patients with neutropenia have to be exerted carefully.

\section{Heparin}

Retrospective trials in patients with sepsis have shown a reduction in mortality using unfractionated heparin [170]. 
The prospective randomized controlled HETRASE study has investigated treatment with low-dose heparin $(500 \mathrm{IU} / \mathrm{h}$ during 7 days) in 319 patients with sepsis [77]. No influence on 28-day all-cause mortality was found. This trial was characterized by low mortality, perhaps explained by liberal inclusion criteria. Treatment was discontinued when the partial thromboplastin time exceeded $60 \mathrm{~s}$. Under these conditions, the administration of low-dose heparin was safe. Further trials including more patients and defined subgroups are needed before recommendations for the use of heparin in neutropenic sepsis can be made (CI).

\section{Antithrombin}

Antithrombin has anti-thrombotic and anti-inflammatory properties. Based on the negative data from the KyberSept trial [165], a Cochrane analysis [4], and subgroup analyses of several trials $[72,87,167]$, we do not recommend the routine use of antithrombin as treatment of neutropenic sepsis in the absence of disseminated intravascular coagulation (DIC; DI). However, in patients with DIC and sepsis, the administration of antithrombin may be considered (BII) [87].

\section{Activated protein C (APC)}

In response to the results of the PROWESS-SHOCK trial [136], APC is no longer in use.

\section{Thrombomodulin}

Thrombomodulin decreases thrombus formation, activates protein $\mathrm{C}$ and has anti-inflammatory properties $[2,119,148$, 161]. Results from a phase IIb study suggested efficacy in patients with sepsis and suspected DIC [161]. However, safety and efficacy is not known in cytopenic patients, and no evidence-based recommendation can be made.

\section{Cytokines and haematopoietic growth factors (G-CSF, GM-CSF)}

The central role of cytokines during the hyper- and antiinflammatory phases of sepsis prompted clinical studies on the use of cytokines and cytokine inhibitors as therapeutic agents. However, studies on the therapeutic efficacy of IL-1 receptor antagonist, TNF-inhibitors, TLR-4 inhibitors and interferon gamma did not show a clinical benefit (EI) [52, 53, 117, 121, 139].

The known effect of G-CSF and GM-CSF in increasing the number of circulating granulocytes was the rationale for clinical studies assessing their role as additional therapy to antibiotics in febrile patients with chemotherapy-induced neutropenia. A meta-analysis of 13 randomized controlled trials including a total of 1,518 patients showed that G-CSF/GM-
Table 5 Summary of treatment recommendations given by the Infectious Diseases Working Party of the German Society of Hematology and Medical Oncology (AGIHO)

\begin{tabular}{ll}
\hline Recommendation & $\begin{array}{l}\text { Evidence } \\
\text { level }\end{array}$ \\
\hline
\end{tabular}

Antimicrobial treatment

Initial treatment with meropenem or with imipenem/ cilastatin or with piperacillin/tazobactam

A combination treatment with an aminoglycoside in AIII neutropenic patients with septic shock and severe sepsis may be considered

Cardiovascular insufficiency

Albumin-containing solutions may be used in patients with $\mathrm{CII}$ sepsis and septic shock

The drug of choice to elevate the vasotonus is norepinephrine

In case of sepsis-related myocardial depression leading to low cardiac output despite adequate volume substitution, vasopressor treatment with dobutamine should be instituted

Treatment of pulmonary failure

Non-invasive positive pressure ventilation (CPAP or bilevel AII positive airway pressure) should be preferred if possible in patients without hypotension or altered mental status

An early start of non-invasive ventilation, prior to development of severe hypoxaemia, is favourable

Management of renal dysfunction

Intermittent haemodialysis and continuous renal replacement therapies are equivalent

No firm recommendations can be given for the use of increased doses of renal replacement therapy

Low-dose dopamine for protection of renal function is not EI recommended

Nutrition and control of metabolic functions

Enteral nutrition is preferred over parenteral nutrition

During initial phase of sepsis, energy supply should not DIII exceed 20-25 kcal/kg ideal bodyweight (IBW)

During recovery, $25-30 \mathrm{kcal} / \mathrm{kg}$ IBW should be provided

We do not recommend general use of arginine, omega-3 fatty acids and combined formulations in patients with severe sepsis and septic shock

Glutamine substitution cannot be recommended in patients EI with severe sepsis and septic shock

Further clinical trials regarding the adequate dosing and treatment duration are needed before treatment with selenium can be recommended

Aiming at strictly normal blood glucose level of 4.4 $6.6 \mathrm{mmol} / \mathrm{L}(80-120 \mathrm{mg} / \mathrm{dL})$ is not recommended Blood glucose levels should be kept $\leq 9.9 \mathrm{mmol} / \mathrm{L}$ $(\leq 180 \mathrm{mg} / \mathrm{dL})$ in septic neutropenic patients

A high variability of blood glucose levels in septic patients BIII should be avoided, as this is associated with increased mortality

Corticosteroids

High-dose corticosteroids should not be used in neutropenic or non-neutropenic septic patients

The routine use of substitutive doses of hydrocortisone in neutropenic patients with sepsis is not recommended Low-dose corticoid treatment may be considered in patients BII with insufficient restoration of blood pressure levels despite adequate fluid resuscitation and vasopressor treatment BII

BIII

BIII EI BII

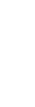


Table 5 (continued)

\begin{tabular}{|c|c|}
\hline Recommendation & $\begin{array}{l}\text { Evidence } \\
\text { level }\end{array}$ \\
\hline \multicolumn{2}{|l|}{ Treatment with coagulation inhibitors } \\
\hline $\begin{array}{l}\text { Further trials on the use of low-dose heparin ( } 500 \mathrm{IU} / \mathrm{h} \text { for } \\
7 \text { days) are needed before recommendations can be made }\end{array}$ & CI \\
\hline $\begin{array}{l}\text { Routine use of antithrombin is not recommended as } \\
\text { treatment of sepsis in neutropenic patients antithrombin } \\
\text { may be considered during DIC and sepsis }\end{array}$ & $\begin{array}{l}\text { DI } \\
\text { BII }\end{array}$ \\
\hline \multicolumn{2}{|l|}{ Growth factors and immunoglobulins } \\
\hline $\begin{array}{l}\text { The routine additional use of G-CSF or GM-CSF as } \\
\text { standard treatment of sepsis in neutropenia is not } \\
\text { recommended }\end{array}$ & DI \\
\hline $\begin{array}{l}\text { There is moderate degree of evidence to support the use of } \\
\text { i.v. immunoglobulins in sepsis }\end{array}$ & BII \\
\hline \multicolumn{2}{|l|}{ Transfusion management } \\
\hline $\begin{array}{l}\text { The cut-off for substitution of platelets is often set to a } \\
\text { higher value (platelets } 20,000 / \mu \mathrm{L} \text { instead of } 10,000 / \mu \mathrm{L} \\
\text { during sepsis) }\end{array}$ & BIII \\
\hline $\begin{array}{l}\text { A transfusion trigger of }<9 \mathrm{~g} / \mathrm{dL} \text { haemoglobin during } \\
\text { neutropenic sepsis is recommended }\end{array}$ & BIII \\
\hline
\end{tabular}

CSF effectively reduces the time to neutrophil recovery and the length of hospitalization [36]. However, despite a marginally significant benefit for the use of G-CSF/GM-CSF in reducing infection-related mortality, overall mortality appeared not to be influenced. Even though this meta-analysis reported only mild side effects associated with G-CSF/GMCSF treatment (bone pain, joint pain and flue-like symptoms), there is an accumulating number of publications on respiratory deterioration with ARDS during G-CSF/GM-CSF-induced neutropenia recovery [17, 18, 83, 147]. In non-neutropenic patients with pneumonia or sepsis, G-CSF/GM-CSF appeared to be safe but ineffective in reducing mortality rates or complications from infection $[141,169]$. On the basis of the current studies and reports, we do not recommend the routine additional use of G-CSF or GM-CSF to standard treatment of sepsis in neutropenia (DI). Although GM-CSF seems to be able to reverse sepsis-induced immune paralysis, it is currently not available for treatment in the EU $[110,143]$.

Immunoglobulins

The treatment of sepsis in neutropenia with i.v. immunoglobulin's (IVIG) did not show a significant difference in survival in a randomized controlled trial [65]. A meta-analysis on trials of IVIG in patients with sepsis identified 20 trials eligible for evaluation [156]. Compared with placebo or no intervention, the use of polyclonal IVIG was associated with a survival benefit (relative risk 0.74). The number needed to treat to save one life was nine. Interestingly, more severely ill patients, those receiving treatment for more than 2 days and those receiving $\geq 1 \mathrm{~g} / \mathrm{kg}$, seemed to benefit most. As most of the individual trials analyzed had flaws in design, were rather small or performed during a time when the standard of care for septic patients was different from today; the authors conclude that a large randomized controlled trial should be performed [156]. Three additional meta-analyses investigated the use of IVIG during sepsis and had similar outcomes [90, 94, 151]. In conclusion, there is moderate degree of evidence to support the use of IVIG in sepsis (BII).

\section{Granulocyte transfusions}

Several case reports and phase I/II studies have shown some efficacy of granulocyte transfusions in patients with infections during severe neutropenia including patients with invasive fungal infections. However, complications have been reported as well, e.g. fatal CMV infection, allo-immunization and the transfusion-related acute lung injury syndrome. Recently, a randomized controlled trial has been published [101]. It failed to show any beneficial effect, but it was small, and the authors discussed several problems associated with the design of the trial. A meta-analysis of the use of granulocyte transfusion in neutropenic neonates yielded equivocal results [123]. Taken together, at this time, no recommendation can be given on the use of granulocyte transfusions outside of clinical trials.

\section{Transfusion management in sepsis}

The recommendations for substituting platelets or packed red blood cell in neutropenic patients can be applied to those patients developing sepsis as well. However, the cutoff for substitution is often set to higher values (platelets $20,000 / \mu \mathrm{L}$ instead of $10,000 / \mu \mathrm{L} ; \mathrm{BIII})$. A randomized trial in children with sepsis showed no difference in outcome between a liberal $(<9.5 \mathrm{~g} / \mathrm{dL})$ and a restrictive $(<7 \mathrm{~g} / \mathrm{dL})$ trigger for erythrocyte transfusion [82]. Although there are no prospective randomized studies available, we recommend a transfusion trigger of $<9 \mathrm{~g} / \mathrm{dL}$ haemoglobin level to optimize tissue oxygenation (there was no consensus inside the panel of experts regarding the strength of recommendation) [166].

\section{Summary of recommendations}

Table 5 summarizes treatment recommendations given by the AGIHO.

Funding The AGIHO received no sponsoring for the preparation of these guidelines. Travel expenses were covered by the German Society of Hematology and Medical Oncology.

Disclosure Olaf Penack: research funding-Bio Rad, Fresenius biotech, Gentium, Genzyme, Gilead.

Pierre Fabre: consultant-MSD; lecture honoraria/travel grantsAstellas, Gilead, Pfizer, MSD. 
Carolin Becker: Travel Grants: Gilead Dieter Buchheidt: research funding - Gilead Sciences, Pfizer; consultant - Gilead Sciences; lecture honoraria/travel grants-Astellas, Gilead Sciences, MSD, Pfizer.

Michael Kiehl: consultant — Gilead, MSD, Roche, Janssen; lecture honoraria/travel grants - Gilead, MSD, Roche, Merck, Cellgene.

Marie von Lilienfeld-Toal: research funding-MSD, Gilead, Pfizer; consultant-MSD; lecture honoraria/travel grants-MSD, Astellas, Gilead, Janssen Cilag.

Marcus Hentrich: consultant-Takeda; lecture honoraria/travel grants - Gilead, MSD, Pfizer.

Marc Reinwald: research funding - Gilead, Pfizer; honoraria/travel grants-Astellas, MSD, Roche, Celgene.

Martin Schmidt-Hieber: lecture honoraria/travel grants-Gilead, Bristol Myers Squibb, MSD.

Thomas Weber: consultant—MSD; lecture honoraria/travel grantsAstellas.

Conflict of interest All remaining authors have declared no conflicts of interest.

Open Access This article is distributed under the terms of the Creative Commons Attribution License which permits any use, distribution, and reproduction in any medium, provided the original author(s) and the source are credited.

\section{References}

1. Aarts MJ, Peters FP, Mandigers CM et al. (2013) Primary granulocyte colony-stimulating factor prophylaxis during the first two cycles only or throughout all chemotherapy cycles in patients with breast cancer at risk for febrile neutropenia. J Clin Oncol 31(34): 4290-4296

2. Abeyama K, Stern DM, Ito Y et al (2005) The N-terminal domain of thrombomodulin sequesters high-mobility group-B1 protein, a novel antiinflammatory mechanism. J Clin Invest 115:1267-1274

3. Adda M, Coquet I, Darmon M et al (2008) Predictors of noninvasive ventilation failure in patients with hematologic malignancy and acute respiratory failure. Crit Care Med 36:2766-2772

4. Afshari A, Wetterslev J, Brok J et al. (2008) Antithrombin III for critically ill patients. Cochrane Database Syst Rev 16(3):CD005370

5. Ahn S, Lee YS, Chun YH et al (2011) Predictive factors of poor prognosis in cancer patients with chemotherapy-induced febrile neutropenia. Support Care Cancer 19:1151-1158

6. Ahn S, Lee YS, Lim KS et al (2013) Adding procalcitonin to the MASCC risk-index score could improve risk stratification of patients with febrile neutropenia. Support Care Cancer Off J Multinatl Assoc Support Care Cancer 21:2303-2308

7. Ali NA, O'brien JM Jr, Dungan K et al (2008) Glucose variability and mortality in patients with sepsis. Crit Care Med 36:2316-2321

8. Ammann RA, Zucol F, Aebi C et al (2007) Real-time broad-range PCR versus blood culture. A prospective pilot study in pediatric cancer patients with fever and neutropenia. Support Care Cancer Off J Multinatl Assoc Support Care Cancer 15:637-641

9. Andrews PJ, Avenell A, Noble DW et al (2011) Randomised trial of glutamine, selenium, or both, to supplement parenteral nutrition for critically ill patients. BMJ 342:d1542

10. Angstwurm MW, Engelmann L, Zimmermann T et al (2007) Selenium in Intensive Care (SIC): results of a prospective randomized, placebo-controlled, multiple-center study in patients with severe systemic inflammatory response syndrome, sepsis, and septic shock. Crit Care Med 35:118-126
11. Angus DC, Van Der Poll T (2013) Severe sepsis and septic shock. N Engl J Med 369:840-851

12. Annane D, Bellissant E, Bollaert PE et al (2009) Corticosteroids in the treatment of severe sepsis and septic shock in adults: a systematic review. JAMA 301:2362-2375

13. Annane D, Cariou A, Maxime V et al (2010) Corticosteroid treatment and intensive insulin therapy for septic shock in adults: a randomized controlled trial. JAMA 303:341-348

14. Annane D, Sebille V, Charpentier C et al (2002) Effect of treatment with low doses of hydrocortisone and fludrocortisone on mortality in patients with septic shock. JAMA 288:862-871

15. Anonymous (2001) Guidelines for the management of severe sepsis and septic shock. The International Sepsis Forum. Intensive Care Med 27(Suppl 1):S1-134

16. Apostolopoulou E, Raftopoulos V, Terzis $\mathrm{K}$ et al (2010) Infection Probability Score, APACHE II and KARNOFSKY scoring systems as predictors of bloodstream infection onset in hematologyoncology patients. BMC Infect Dis 10:135

17. Arimura K, Inoue H, Kukita $\mathrm{T}$ et al (2005) Acute lung injury in a healthy donor during mobilization of peripheral blood stem cells using granulocyte-colony stimulating factor alone. Haematologica 90:ECR10

18. Azoulay E, Darmon M, Delclaux C et al (2002) Deterioration of previous acute lung injury during neutropenia recovery. Crit Care Med 30:781-786

19. Azoulay E, Mokart D, Pene F et al (2013) Outcomes of critically ill patients with hematologic malignancies: prospective multicenter data from france and belgium - a groupe de recherche respiratoire en reanimation onco-hematologique study. J Clin Oncol Off J Am Soc Clin Oncol 31:2810-2818

20. Azoulay E, Schlemmer B (2006) Diagnostic strategy in cancer patients with acute respiratory failure. Intensive Care Med 32: 808-822

21. Azoulay E, Thiery G, Chevret S et al (2004) The prognosis of acute respiratory failure in critically ill cancer patients. Medicine (Baltimore) 83:360-370

22. Bagshaw SM, Bellomo R, Jacka MJ et al (2009) The impact of early hypoglycemia and blood glucose variability on outcome in critical illness. Crit Care 13:R91

23. Bagshaw SM, Egi M, George C et al (2009) Early blood glucose control and mortality in critically ill patients in Australia. Crit Care Med 37:463-470

24. Barbosa VM, Miles EA, Calhau C et al (2010) Effects of a fish oil containing lipid emulsion on plasma phospholipid fatty acids, inflammatory markers, and clinical outcomes in septic patients: a randomized, controlled clinical trial. Crit Care 14:R5

25. Beale R, Janes JM, Brunkhorst FM et al (2010) Global utilization of low-dose corticosteroids in severe sepsis and septic shock: a report from the PROGRESS registry. Crit Care 14:R102

26. Bellomo R, Chapman M, Finfer S et al (2000) Low-dose dopamine in patients with early renal dysfunction: a placebocontrolled randomised trial. Australian and New Zealand Intensive Care Society (ANZICS) Clinical Trials Group. Lancet 356:2139-2143

27. Bertolini G, Iapichino G, Radrizzani D et al (2003) Early enteral immunonutrition in patients with severe sepsis: results of an interim analysis of a randomized multicentre clinical trial. Intensive Care Med 29:834-840

28. Bone RC, Fisher CJ Jr, Clemmer TP et al (1987) A controlled clinical trial of high-dose methylprednisolone in the treatment of severe sepsis and septic shock. N Engl J Med 317:653-658

29. Bos MM, Smeets LS, Dumay I et al (2013) Bloodstream infections in patients with or without cancer in a large community hospital. Infection 41:949-958

30. Bossaer JB, Hall PD, Garrett-Mayer E (2010) Incidence of vancomycin-resistant enterococci (VRE) infection in high-risk 
febrile neutropenic patients colonized with VRE. Support Care Cancer Off J Multinatl Assoc Support Care Cancer 19:231-237

31. Bower RH, Cerra FB, Bershadsky B et al (1995) Early enteral administration of a formula (Impact) supplemented with arginine, nucleotides, and fish oil in intensive care unit patients: results of a multicenter, prospective, randomized, clinical trial. Crit Care Med 23:436-449

32. Brunkhorst FM, Engel C, Bloos F et al (2008) Intensive insulin therapy and pentastarch resuscitation in severe sepsis. N Engl J Med 358:125-139

33. Casserly B, Gerlach H, Phillips GS et al (2012) Low-dose steroids in adult septic shock: results of the Surviving Sepsis Campaign. Intensive Care Med 38:1946-1954

34. Chaberny IF, Ruseva E, Sohr D et al (2009) Surveillance with successful reduction of central line-associated bloodstream infections among neutropenic patients with hematologic or oncologic malignancies. Ann Hematol 88:907-912

35. Christopeit M, Penack O, Ostermann H (2011) Steroids in neutropenic patients with sepsis - comment on 'How I manage hematology patients with septic shock' by Jon Cohen and Stephen Drage. Br J Haematol 155:624-625, author reply 625-626

36. Clark OA, Lyman GH, Castro AA et al (2005) Colony-stimulating factors for chemotherapy-induced febrile neutropenia: a metaanalysis of randomized controlled trials. J Clin Oncol Off J Am Soc Clin Oncol 23:4198-4214

37. Conti G, Marino P, Cogliati A et al (1998) Noninvasive ventilation for the treatment of acute respiratory failure in patients with hematologic malignancies: a pilot study. Intensive Care Med 24:12831288

38. Cooper DJ, Walley KR, Wiggs BR et al (1990) Bicarbonate does not improve hemodynamics in critically ill patients who have lactic acidosis. A prospective, controlled clinical study. Ann Intern Med 112:492-498

39. Cronin L, Cook DJ, Carlet J et al (1995) Corticosteroid treatment for sepsis: a critical appraisal and meta-analysis of the literature. Crit Care Med 23:1430-1439

40. Delaney AP, Dan A, Mccaffrey J et al (2011) The role of albumin as a resuscitation fluid for patients with sepsis: a systematic review and meta-analysis. Crit Care Med 39:386-391

41. Dellinger RP, Levy MM, Carlet JM et al (2008) Surviving Sepsis Campaign: international guidelines for management of severe sepsis and septic shock: 2008. Intensive Care Med 34:17-60

42. Dellinger RP, Levy MM, Carlet JM et al (2008) Surviving Sepsis Campaign: international guidelines for management of severe sepsis and septic shock: 2008. Crit Care Med 36:296-327

43. Dellinger RP, Levy MM, Rhodes A et al (2013) Surviving Sepsis Campaign: international guidelines for management of severe sepsis and septic shock, 2012. Intensive Care Med 39:165-228

44. Dellinger RP, Levy MM, Rhodes A et al (2013) Surviving sepsis campaign: international guidelines for management of severe sepsis and septic shock: 2012. Crit Care Med 41:580-637

45. Dettenkofer M, Ebner W, Bertz H et al (2003) Surveillance of nosocomial infections in adult recipients of allogeneic and autologous bone marrow and peripheral blood stem-cell transplantation. Bone Marrow Transplant 31:795-801

46. Egi M, Bellomo R, Stachowski E et al (2006) Variability of blood glucose concentration and short-term mortality in critically ill patients. Anesthesiology 105:244-252

47. Falciglia M, Freyberg RW, Almenoff PL et al (2009) Hyperglycemia-related mortality in critically ill patients varies with admission diagnosis. Crit Care Med 37:3001-3009

48. Feld R (2008) Bloodstream infections in cancer patients with febrile neutropenia. Int J Antimicrob Agents 32(Suppl 1):S30-33

49. Ferrer R, Artigas A, Levy MM et al (2008) Improvement in process of care and outcome after a multicenter severe sepsis educational program in Spain. JAMA 299:2294-2303
50. Finfer S, Bellomo R, Boyce N et al (2004) A comparison of albumin and saline for fluid resuscitation in the intensive care unit. N Engl J Med 350:2247-2256

51. Finfer S, Chittock DR, Su SY et al (2009) Intensive versus conventional glucose control in critically ill patients. N Engl J Med 360: 1283-1297

52. Fisher CJ Jr, Dhainaut JF, Opal SM et al (1994) Recombinant human interleukin 1 receptor antagonist in the treatment of patients with sepsis syndrome. Results from a randomized, double-blind, placebo-controlled trial. Phase III rhIL-1ra Sepsis Syndrome Study Group. JAMA J Am Med Assoc 271:1836-1843

53. Fisher CJ Jr, Slotman GJ, Opal SM et al (1994) Initial evaluation of human recombinant interleukin-1 receptor antagonist in the treatment of sepsis syndrome: a randomized, open-label, placebocontrolled multicenter trial. Crit Care Med 22:12-21

54. Flowers CR, Seidenfeld J, Bow EJ et al (2013) Antimicrobial prophylaxis and outpatient management of fever and neutropenia in adults treated for malignancy: American Society of Clinical Oncology clinical practice guideline. J Clin Oncol Off J Am Soc Clin Oncol 31:794-810

55. Freifeld AG, Bow EJ, Sepkowitz KA et al (2011) Clinical practice guideline for the use of antimicrobial agents in neutropenic patients with cancer: 2010 update by the infectious diseases society of america. Clin infect Dis Off Publ Infect Dis Soc Am 52:e56-93

56. Galban C, Montejo JC, Mesejo A et al (2000) An immuneenhancing enteral diet reduces mortality rate and episodes of bacteremia in septic intensive care unit patients. Crit Care Med 28:643648

57. Gasparovic V, Filipovic-Grcic I, Merkler M et al (2003) Continuous renal replacement therapy (CRRT) or intermittent hemodialysis (IHD) - what is the procedure of choice in critically ill patients? Ren Fail 25:855-862

58. Ghahramani N, Shadrou S, Hollenbeak C (2008) A systematic review of continuous renal replacement therapy and intermittent haemodialysis in management of patients with acute renal failure. Nephrol (Carlton) 13:570-578

59. Gorjup V, Fister M, Noc M et al (2012) Treatment of sepsis and ARDS with extracorporeal membrane oxygenation and interventional lung assist membrane ventilator in a patient with acute lymphoblastic leukemia. Respir Care 57:1178-1181

60. Green RS, Djogovic D, Gray S et al (2008) Canadian Association of Emergency Physicians Sepsis Guidelines: the optimal management of severe sepsis in Canadian emergency departments. CJEM 10: 443-459

61. Griesdale DE, De Souza RJ, Van Dam RM et al (2009) Intensive insulin therapy and mortality among critically ill patients: a metaanalysis including NICE-SUGAR study data. Cmaj 180:821-827

62. Guidet B, Martinet O, Boulain T et al (2012) Assessment of hemodynamic efficacy and safety of $6 \%$ hydroxyethylstarch $130 / 0.4$ vs. $0.9 \% \mathrm{NaCl}$ fluid replacement in patients with severe sepsis: the CRYSTMAS study. Crit Care 16:R94

63. Hamalainen S, Juutilainen A, Kuittinen T et al (2010) Serum aminoterminal pro-brain natriuretic peptide in hematological patients with neutropenic fever: a prospective comparison with $\mathrm{C}$-reactive protein. Leuk Lymphoma 51:1040-1046

64. Hamalainen S, Kuittinen T, Matinlauri I et al (2008) Neutropenic fever and severe sepsis in adult acute myeloid leukemia (AML) patients receiving intensive chemotherapy: causes and consequences. Leuk Lymphoma 49:495-501

65. Hentrich M, Fehnle K, Ostermann H et al (2006) IgMA-enriched immunoglobulin in neutropenic patients with sepsis syndrome and septic shock: a randomized, controlled, multiple-center trial. Crit Care Med 34:1319-1325

66. Heyland D, Muscedere J, Wischmeyer PE et al (2013) A randomized trial of glutamine and antioxidants in critically ill patients. $\mathrm{N}$ Engl J Med 368:1489-1497 
67. Heyland DK, Dhaliwal R, Drover JW et al (2003) Canadian clinical practice guidelines for nutrition support in mechanically ventilated, critically ill adult patients. JPEN J Parenter Enteral Nutr 27:355-373

68. Heyland DK, Novak F, Drover JW et al (2001) Should immunonutrition become routine in critically ill patients? A systematic review of the evidence. JAMA J Am Med Assoc 286:944 953

69. Hilbert G, Gruson D, Vargas F et al (2000) Noninvasive continuous positive airway pressure in neutropenic patients with acute respiratory failure requiring intensive care unit admission. Crit Care Med 28:3185-3190

70. Hilbert G, Gruson D, Vargas F et al (2001) Noninvasive ventilation in immunosuppressed patients with pulmonary infiltrates, fever, and acute respiratory failure. N Engl J Med 344:481-487

71. Hirsch HH, Martino R, Ward KN et al (2013) Fourth European Conference on Infections in Leukaemia (ECIL-4): guidelines for diagnosis and treatment of human respiratory syncytial virus, parainfluenza virus, metapneumovirus, rhinovirus, and coronavirus. Clin Infect Dis Off Publ Infect Dis Soc Am 56:258-266

72. Hoffmann JN, Wiedermann CJ, Juers M et al (2006) Benefit/risk profile of high-dose antithrombin in patients with severe sepsis treated with and without concomitant heparin. Thromb Haemost 95:850-856

73. Horn DL, Morrison DC, Opal SM et al (2000) What are the microbial components implicated in the pathogenesis of sepsis? Report on a symposium. Clin Infect Dis Off Publ Infect Dis Soc Am 31:851-858

74. Huang TS, Shyu YC, Chen HY et al (2013) Effect of parenteral selenium supplementation in critically ill patients: a systematic review and meta-analysis. PLoS One 8:e54431

75. Investigators RRTS, Bellomo R, Cass A et al (2009) Intensity of continuous renal-replacement therapy in critically ill patients. $\mathrm{N}$ Engl J Med 361:1627-1638

76. Jacobi J, Bircher N, Krinsley J et al (2012) Guidelines for the use of an insulin infusion for the management of hyperglycemia in critically ill patients. Crit Care Med 40:3251-3276

77. Jaimes F, De La Rosa G, Morales C et al (2009) Unfractioned heparin for treatment of sepsis: a randomized clinical trial (The HETRASE Study). Crit Care Med 37:1185-1196

78. Jeddi R, Achour M, Amor RB et al (2010) Factors associated with severe sepsis: prospective study of 94 neutropenic febrile episodes. Hematology 15:28-32

79. John S, Eckardt KU (2007) Renal replacement strategies in the ICU. Chest 132:1379-1388

80. Kalil AC (2010) Wanted: early goal-directed therapy for septic shock - dead or alive, but not critically ill! Intensive Care Med 36: $1-3$

81. Kang CI, Song JH, Chung DR et al (2011) Risk factors and pathogenic significance of severe sepsis and septic shock in 2286 patients with gram-negative bacteremia. J Infect 62:26-33

82. Karam O, Tucci M, Ducruet T et al (2011) Red blood cell transfusion thresholds in pediatric patients with sepsis. Pediatr Crit Care Med J Soc Crit Care Med World Fed Pediatr Intensiv Crit Care Soc 12:512-518

83. Karlin L, Darmon M, Thiery G et al (2005) Respiratory status deterioration during G-CSF-induced neutropenia recovery. Bone Marrow Transplant 36:245-250

84. Kellum JA, Angus DC, Johnson JP et al (2002) Continuous versus intermittent renal replacement therapy: a meta-analysis. Intensive Care Med 28:29-37

85. Kellum JA, Decker JM (2001) Use of dopamine in acute renal failure: a meta-analysis. Crit Care Med 29:1526-1531

86. Kielstein JT, Burkhardt O (2011) Dosing of antibiotics in critically ill patients undergoing renal replacement therapy. Curr Pharm Biotechnol 12:2015-2019
87. Kienast J, Juers M, Wiedermann CJ et al (2006) Treatment effects of high-dose antithrombin without concomitant heparin in patients with severe sepsis with or without disseminated intravascular coagulation. J Thromb Haemost: JTH 4:90-97

88. Kish MA (2001) Guide to development of practice guidelines. Clin Infect Dis Off Publ Infect Dis Soc Am 32:851-854

89. Kreymann KG, Berger MM, Deutz NE et al (2006) ESPEN Guidelines on Enteral Nutrition: intensive care. Clin Nutr 25:210 223

90. Kreymann KG, De Heer G, Nierhaus A et al (2007) Use of polyclonal immunoglobulins as adjunctive therapy for sepsis or septic shock. Crit Care Med 35:2677-2685

91. Krishnan JA, Parce PB, Martinez A et al (2003) Caloric intake in medical ICU patients: consistency of care with guidelines and relationship to clinical outcomes. Chest 124:297-305

92. Kumar A, Zarychanski R, Light B et al (2010) Early combination antibiotic therapy yields improved survival compared with monotherapy in septic shock: a propensity-matched analysis. Crit Care Med 38:1773-1785

93. Lamoth F, Jaton K, Prod'hom G et al (2010) Multiplex blood PCR in combination with blood cultures for improvement of microbiological documentation of infection in febrile neutropenia. J Clin Microbiol 48:3510-3516

94. Laupland KB, Kirkpatrick AW, Delaney A (2007) Polyclonal intravenous immunoglobulin for the treatment of severe sepsis and septic shock in critically ill adults: a systematic review and metaanalysis. Crit Care Med 35:2686-2692

95. Legrand M, Max A, Peigne V et al (2012) Survival in neutropenic patients with severe sepsis or septic shock. Crit Care Med 40:43-49

96. Levi M, Toh CH, Thachil J et al (2009) Guidelines for the diagnosis and management of disseminated intravascular coagulation. British Committee for Standards in Hematology. Br J Hematol 145:24-33

97. Levy MM, Fink MP, Marshall JC et al (2003) 2001 SCCM/ESICM/ ACCP/ATS/SIS International Sepsis Definitions Conference. Crit Care Med 31:1250-1256

98. Levy MM, Fink MP, Marshall JC et al (2003) 2001 SCCM/ESICM/ ACCP/ATS/SIS International Sepsis Definitions Conference. Intensive Care Med 29:530-538

99. Li MJ, Yang YL, Huang SC et al (2011) Successful extracorporeal membrane oxygenation support patients with malignancy and septic shock. Pediatr Blood Cancer 57:697

100. Lins RL, Elseviers MM, Van Der Niepen P et al (2009) Intermittent versus continuous renal replacement therapy for acute kidney injury patients admitted to the intensive care unit: results of a randomized clinical trial. Nephrol Dial Transplant 24:512-518

101. Liss BJ, Vehreschild JJ, Cornely OA et al (2012) Intestinal colonisation and blood stream infections due to vancomycin-resistant enterococci (VRE) and extended-spectrum beta-lactamaseproducing Enterobacteriaceae (ESBLE) in patients with haematological and oncological malignancies. Infection 40:613-619

102. Ljungman P, De La Camara R, Perez-Bercoff L et al (2011) Outcome of pandemic H1N1 infections in hematopoietic stem cell transplant recipients. Haematologica 96:1231-1235

103. Lynn JJ, Chen KF, Weng YM et al (2013) Risk factors associated with complications in patients with chemotherapy-induced febrile neutropenia in emergency department. Hematol Oncol 31(4):189196

104. Maertens J, Marchetti O, Herbrecht R et al (2011) European guidelines for antifungal management in leukemia and hematopoietic stem cell transplant recipients: summary of the ECIL 3-2009 update. Bone Marrow Transplant 46:709-718

105. Mancini N, Clerici D, Diotti R et al (2008) Molecular diagnosis of sepsis in neutropenic patients with haematological malignancies. J Med Microbiol 57:601-604

106. Marik PE, Pastores SM, Annane D et al (2008) Recommendations for the diagnosis and management of corticosteroid insufficiency in 
critically ill adult patients: consensus statements from an international task force by the American College of Critical Care Medicine. Crit Care Med 36:1937-1949

107. Maschmeyer G, Beinert T, Buchheidt D et al (2009) Diagnosis and antimicrobial therapy of lung infiltrates in febrile neutropenic patients: guidelines of the infectious diseases working party of the German Society of Hematology and Oncology. Eur J Cancer 45: 2462-2472

108. Mathieu D, Neviere R, Billard V et al (1991) Effects of bicarbonate therapy on hemodynamics and tissue oxygenation in patients with lactic acidosis: a prospective, controlled clinical study. Crit Care Med 19:1352-1356

109. Mato AR, Luger SM, Heitjan DF et al (2010) Elevation in serum lactate at the time of febrile neutropenia (FN) in hemodynamicallystable patients with hematologic malignancies (HM) is associated with the development of septic shock within 48 hours. Cancer Biol Ther 9:585-589

110. Meisel C, Schefold JC, Pschowski R et al (2009) Granulocytemacrophage colony-stimulating factor to reverse sepsis-associated immunosuppression: a double-blind, randomized, placebocontrolled multicenter trial. Am J Respir Crit Care Med 180:640-648

111. Meister B, Zelger B, Kropshofer G et al (2010) Extracorporeal membrane oxygenation as a rescue therapy for leukaemic children with pulmonary failure. Br J Hematol 148:126-131

112. Mesters RM, Mannucci PM, Coppola R et al (1996) Factor VIIa and antithrombin III activity during severe sepsis and septic shock in neutropenic patients. Blood 88:881-886

113. Minneci PC, Deans KJ, Banks SM et al (2004) Meta-analysis: the effect of steroids on survival and shock during sepsis depends on the dose. Ann Intern Med 141:47-56

114. Minneci PC, Deans KJ, Eichacker PQ et al (2009) The effects of steroids during sepsis depend on dose and severity of illness: an updated meta-analysis. Clin Microbiol Infect Off Publ Eur Soc Clin Microbiol Infect Dis 15:308-318

115. Montassier E, Batard E, Gastinne T et al (2013) Recent changes in bacteremia in patients with cancer: a systematic review of epidemiology and antibiotic resistance. Eur J Clin Microbiol Infect Dis Off Publ Eur Soc Clin Microbiol 32:841-850

116. Moran JL, Graham PL, Rockliff S et al (2010) Updating the evidence for the role of corticosteroids in severe sepsis and septic shock: a Bayesian meta-analytic perspective. Crit Care 14:R134

117. Morris PE, Zeno B, Bernard AC et al (2012) A placebo-controlled, double-blind, dose-escalation study to assess the safety, tolerability and pharmacokinetics/pharmacodynamics of single and multiple intravenous infusions of AZD9773 in patients with severe sepsis and septic shock. Crit Care 16:R31

118. Mousset S, Buchheidt D, Heinz W et al. (2013) Treatment of invasive fungal infections in cancer patients-updated recommendations of the Infectious Diseases Working Party (AGIHO) of the German Society of Hematology and Oncology (DGHO). Ann Hematol 93(1):13-32

119. Nagato M, Okamoto K, Abe Y et al (2009) Recombinant human soluble thrombomodulin decreases the plasma high-mobility group box-1 protein levels, whereas improving the acute liver injury and survival rates in experimental endotoxemia. Crit Care Med 37: 2181-2186

120. Nakamura A, Sugimoto Y, Ohishi K et al (2010) Diagnostic value of PCR analysis of bacteria and fungi from blood in empiric-therapyresistant febrile neutropenia. J Clin Microbiol 48:2030-2036

121. Opal SM, Fisher CJ Jr, Dhainaut JF et al (1997) Confirmatory interleukin-1 receptor antagonist trial in severe sepsis: a phase III, randomized, double-blind, placebo-controlled, multicenter trial. The Interleukin-1 Receptor Antagonist Sepsis Investigator Group. Crit Care Med 25:1115-1124

122. Palevsky PM, Zhang JH, O'connor TZ et al (2008) Intensity of renal support in critically ill patients with acute kidney injury. N Engl J Med 359:7-20
123. Pammi M, Brocklehurst P (2011) Granulocyte transfusions for neonates with confirmed or suspected sepsis and neutropenia. Cochrane Database Syst Rev 5(10):CD003956

124. Patel GP, Balk RA (2012) Systemic steroids in severe sepsis and septic shock. Am J Respir Crit Care Med 185:133-139

125. Paul M, Benuri-Silbiger I, Soares-Weiser K et al (2004) Beta lactam monotherapy versus beta lactam-aminoglycoside combination therapy for sepsis in immunocompetent patients: systematic review and meta-analysis of randomised trials. BMJ 328:668

126. Paul M, Dickstein Y, Schlesinger A et al (2013) Beta-lactam versus beta-lactam-aminoglycoside combination therapy in cancer patients with neutropenia. Cochrane Database Syst Rev 6, CD003038

127. Paul M, Soares-Weiser K, Leibovici L (2003) Beta lactam monotherapy versus beta lactam-aminoglycoside combination therapy for fever with neutropenia: systematic review and meta-analysis. BMJ 326:1111

128. Perner A, Haase N, Guttormsen AB et al (2012) Hydroxyethyl starch 130/0.42 versus Ringer's acetate in severe sepsis. N Engl J Med 367:124-134

129. Persson L, Dahl H, Linde A et al (2003) Human cytomegalovirus, human herpesvirus- 6 and human herpesvirus-7 in neutropenic patients with fever of unknown origin. Clin Microbiol Infect Off Publ Eur Soc Clin Microbiol Infect Dis 9:640-644

130. Pontes-Arruda A, Aragao AM, Albuquerque JD (2006) Effects of enteral feeding with eicosapentaenoic acid, gamma-linolenic acid, and antioxidants in mechanically ventilated patients with severe sepsis and septic shock. Crit Care Med 34:2325-2333

131. Pontes-Arruda A, Martins LF, De Lima SM et al (2011) Enteral nutrition with eicosapentaenoic acid, gamma-linolenic acid and antioxidants in the early treatment of sepsis: results from a multicenter, prospective, randomized, double-blinded, controlled study: the INTERSEPT study. Crit Care 15:R144

132. Pottecher T, Calvat S, Dupont $\mathrm{H}$ et al (2006) Haemodynamic management of severe sepsis: recommendations of the French Intensive Care Societies (SFAR/SRLF) Consensus Conference, 13 October 2005, Paris, France. Crit Care 10:311

133. Preiser JC, Devos P, Ruiz-Santana S et al (2009) A prospective randomised multi-centre controlled trial on tight glucose control by intensive insulin therapy in adult intensive care units: the Glucontrol study. Intensive Care Med 35:1738-1748

134. Rabindranath K, Adams J, Macleod AM et al. (2007) Intermittent versus continuous renal replacement therapy for acute renal failure in adults. The Cochrane database of systematic reviews:CD003773

135. Ramzi J, Mohamed Z, Yosr B et al (2007) Predictive factors of septic shock and mortality in neutropenic patients. Hematology 12 : 543-548

136. Ranieri VM, Thompson BT, Barie PS et al (2012) Drotrecogin alfa (activated) in adults with septic shock. N Engl J Med 366:20552064

137. Reinhart K, Brunkhorst FM, Bone HG et al. (2010) Prevention, diagnosis, therapy and follow-up care of sepsis: 1 st revision of S-2k guidelines of the German Sepsis Society (Deutsche SepsisGesellschaft e.V. (DSG)) and the German Interdisciplinary Association of Intensive Care and Emergency Medicine (Deutsche Interdisziplinare Vereinigung fur Intensiv- und Notfallmedizin (DIVI)). German medical science: GMS e-journal 8:Doc14

138. Ricci Z, Ronco C (2008) Dose and efficiency of renal replacement therapy: continuous renal replacement therapy versus intermittent hemodialysis versus slow extended daily dialysis. Crit Care Med 36: S229-237

139. Rice TW, Wheeler AP, Bernard GR et al (2010) A randomized, double-blind, placebo-controlled trial of TAK-242 for the treatment of severe sepsis. Crit Care Med 38:1685-1694

140. Rivers E, Nguyen B, Havstad S et al (2001) Early goal-directed therapy in the treatment of severe sepsis and septic shock. N Engl J Med 345:1368-1377 
141. Root RK, Lodato RF, Patrick W et al (2003) Multicenter, doubleblind, placebo-controlled study of the use of filgrastim in patients hospitalized with pneumonia and severe sepsis. Crit Care Med 31: 367-373

142. Sakr Y, Reinhart K, Vincent JL et al (2006) Does dopamine administration in shock influence outcome? Results of the Sepsis Occurrence in Acutely Ill Patients (SOAP) Study. Crit Care Med 34:589-597

143. Schefold JC, Zeden JP, Pschowski R et al (2010) Treatment with granulocyte-macrophage colony-stimulating factor is associated with reduced indoleamine 2,3-dioxygenase activity and kynurenine pathway catabolites in patients with severe sepsis and septic shock. Scand J Infect Dis 42:164-171

144. Schrier RW, Wang W (2004) Acute renal failure and sepsis. N Engl J Med 351:159-169

145. Sevransky JE, Levy MM, Marini JJ (2004) Mechanical ventilation in sepsis-induced acute lung injury/acute respiratory distress syndrome: an evidence-based review. Crit Care Med 32:S548-553

146. Sherwin RL, Garcia AJ, Bilkovski R (2012) Do low-dose corticosteroids improve mortality or shock reversal in patients with septic shock? A systematic review and position statement prepared for the American Academy of Emergency Medicine. J Emerg Med 43:712

147. Shi B, Liu L, Ye L (2012) Lung injury in a leukemia patient during mobilization of peripheral blood stem cells using granulocyte colony-stimulating factor alone. Ann Hematol 91:469-470

148. Shi CS, Shi GY, Hsiao HM et al (2008) Lectin-like domain of thrombomodulin binds to its specific ligand Lewis $\mathrm{Y}$ antigen and neutralizes lipopolysaccharide-induced inflammatory response. Blood 112:3661-3670

149. Singer P, Berger MM, Van Den Berghe G et al (2009) ESPEN Guidelines on Parenteral Nutrition: intensive care. Clin Nutr 28: 387-400

150. Sligl WI, Milner DA Jr, Sundar S et al (2009) Safety and efficacy of corticosteroids for the treatment of septic shock: a systematic review and meta-analysis. Clin Infect Dis 49:93-101

151. Soares MO, Welton NJ, Harrison DA et al (2012) An evaluation of the feasibility, cost and value of information of a multicentre randomised controlled trial of intravenous immunoglobulin for sepsis (severe sepsis and septic shock): incorporating a systematic review, meta-analysis and value of information analysis. Health Technol Assess 16:1-186

152. Sprung CL, Annane D, Keh D et al (2008) Hydrocortisone therapy for patients with septic shock. N Engl J Med 358:111-124

153. Sprung CL, Caralis PV, Marcial EH et al (1984) The effects of highdose corticosteroids in patients with septic shock. A prospective, controlled study. N Engl J Med 311:1137-1143

154. Steinberg JP, Robichaux C, Tejedor SC et al (2013) Distribution of pathogens in central line-associated bloodstream infections among patients with and without neutropenia following chemotherapy: evidence for a proposed modification to the current surveillance definition. Infect Control Hosp Epidemiol Off J Soc Hosp Epidemiol Am 34:171-175

155. Tonelli M, Manns B, Feller-Kopman D (2002) Acute renal failure in the intensive care unit: a systematic review of the impact of dialytic modality on mortality and renal recovery. Am J Kidney Dis 40:875885

156. Turgeon AF, Hutton B, Fergusson DA et al (2007) Meta-analysis: intravenous immunoglobulin in critically ill adult patients with sepsis. Ann Intern Med 146:193-203

157. Ullmann AJ, Akova M, Herbrecht R et al (2012) ESCMID* guideline for the diagnosis and management of Candida diseases 2012: adults with haematological malignancies and after haematopoietic stem cell transplantation (HCT). Clin Microbiol Infect Off Publ Eur Soc Clin Microbiol Infect Dis 18(Suppl 7):53-67

158. Van Den Berghe G, Wilmer A, Hermans G et al (2006) Intensive insulin therapy in the medical ICU. N Engl J Med 354:449-461

159. Van Den Berghe G, Wouters P, Weekers F et al (2001) Intensive insulin therapy in critically ill patients. N Engl J Med 345:1359-1367

160. Van Wert R, Friedrich JO, Scales DC et al (2010) High-dose renal replacement therapy for acute kidney injury: systematic review and meta-analysis. Crit Care Med 38:1360-1369

161. Vincent JL, Ramesh MK, Ernest D et al (2013) a randomized, double-blind, placebo-controlled, Phase $2 b$ Study to evaluate the safety and efficacy of recombinant human soluble thrombomodulin, ART-123, in patients with sepsis and suspected disseminated intravascular coagulation*. Crit Care Med 41:2069-2079

162. Vincent JL, Sakr Y, Sprung CL et al (2006) Sepsis in European intensive care units: results of the SOAP study. Crit Care Med 34: 344-353

163. Vincent JL, Van Der Linden P, Domb M et al (1987) Dopamine compared with dobutamine in experimental septic shock: relevance to fluid administration. Anesth Analg 66:565-571

164. Von Lilienfeld-Toal M, Lehmann LE, Raadts AD et al (2009) Utility of a commercially available multiplex real-time PCR assay to detect bacterial and fungal pathogens in febrile neutropenia. $\mathrm{J}$ Clin Microbiol 47:2405-2410

165. Warren BL, Eid A, Singer P et al (2001) Caring for the critically ill patient. High-dose antithrombin III in severe sepsis: a randomized controlled trial. JAMA 286:1869-1878

166. Welte M (2009) Erythrocyte transfusion: update of the guidelines "therapy with blood components and plasma derivatives". Anaesthesist 58:1150-1158

167. Wiedermann CJ, Hoffmann JN, Juers M et al (2006) High-dose antithrombin III in the treatment of severe sepsis in patients with a high risk of death: efficacy and safety. Crit Care Med 34:285-292

168. Wisplinghoff $\mathrm{H}$, Seifert H, Wenzel RP et al (2003) Current trends in the epidemiology of nosocomial bloodstream infections in patients with hematological malignancies and solid neoplasms in hospitals in the United States. Clin Infect Dis Off Publ Infect Dis Soc Am 36: $1103-1110$

169. Wunderink R, Leeper K Jr, Schein R et al (2001) Filgrastim in patients with pneumonia and severe sepsis or septic shock. Chest 119:523-529

170. Zarychanski R, Doucette S, Fergusson D et al (2008) Early intravenous unfractionated heparin and mortality in septic shock. Crit Care Med 36:2973-2979

171. Zuber B, Tran TC, Aegerter P et al (2012) Impact of case volume on survival of septic shock in patients with malignancies. Crit Care Med 40:55-62 